\title{
MiDiLLi'DE GELENEKSEL ÇÖMLEKÇiLiK SANATI VE KÜLTÜREL ETKILEŞiM
}

\author{
Yrd. Doç. Cemalettin SEviM*
}

\section{ÖZET}

Ege adaları sosyal, politik ve kültürel olarak çeşitli şekilde ve zaman dilimlerinde Türk ve Yunan halklarının gündemine gelmektedir. İki toplumun kültürü ve geleneği ele alındiğinda birçok benzeşimler ve değerler olduğu görülmektedir. Bu ortak değerlerden biri olan geleneksel el sanatları, toplumların gelenek ve kültürlerini günümüze taşıyan özgün değerlerdir. Toplumlar geleneklerini ve kültürlerini oluştururken başka toplumlardan da etkilenerek kendi kültürel değerleri doğrultusunda geçmiş ile günümüz arasinda köprü kurarlar. Çömlekçilik, toplum ve kültürlerin en eski geleneksel sanatlarındandır. Midillide çömlekçilik üretimi sürmekte ve bu kültür gelecek kuşaklara taşınmaya devam etmektedir. Anadolu kültürü ile de etkileşen Midilli çömlekçilik sanatında; ada kültürü ve yaşamın yansıtan dekorlarla bezenen özgün ürünler ortaya konduğu görülmüştür. Bu makalede Midilli adasındaki kültür, yaşam, kültürler arası etkileşim ve seramik sanatına yansımaları ile adadaki çömlekçi atölyelerinin günümüzdeki durumu değerlendirilerek incelenmektedir.

Anahtar Kelimeler: Seramik, Midilli, çömlekçilik, kültür, etkileşim

\footnotetext{
*Anadolu Üniversitesi, Güzel Sanatlar Fakültesi, Seramik Bölümü, Eskişehir/TÜRKİYE csevim@anadolu.edu.tr
} 


\title{
TRADITIONAL POTTERY AND CULTURAL INTERACTIVITY IN LESVOSISLAND
}

\author{
Assist. Prof. Cemalettin SEViM*
}

\begin{abstract}
Aegean islands come into question for the Turkish and Greek people in various ways and periods of time both socially, politically and culturally. It is observed that there are so many commonalities and shared values when the culture and the traditions of these two culture is discussed. Traditional handcrafts, which is one of these shared values, are the original values which has been brought today. The societies create bridges between past and present by influencing from other societies and according to their own cultural values while creating their traditions and cultures. The art of pottery is one of the oldest traditional art of the societies and cultures. Pottery from the Lesvos's traditional art, continues to the production by transfering its own traditional production and culture to the next generations. Lesvos pottery art wich interacts with Anatolian culture; continues to produce original products with its decorations that is reflecting the culture and life of the island. In this article; Lesvos culture, life on the island, interaction between the cultures and its reflections to the ceramic art and the conditions of the pottery studios are evaluated and researched.
\end{abstract}

Keywords: Ceramic, pottery, Lesvos, culture, interaction

* Anadolu University, Faculty of Fine Arts, Ceramics Department, Eskişehir / TURKEY, csevim@anadolu.edu.tr 


\section{GíRiş}

Midilli (Lesvos), Yunanistan’ın Girit ve Rodos adalarından sonra en büyük üçüncü adasıdır. Feribot ile Ayvalık’a yaklaşık bir saat kırk beş dakika uzaklıktadır. Yeteri kadar tatlı su kaynaklarına sahip olan adanın doğusunda Ghera ve batısında doğal birer liman olan Kallonı körfezleri yer almaktadır. Başlıca geçim kaynakları balıkçılık, zeytincilik ve yoğun olarak da turizmdir. Ada Akdeniz iklimi bitki örtüsü özelliği taşımasından dolayı makiler, zeytin ağaçları ,üzüm bağları, meyve bahçeleri ve çam ağaçlarından oluşan küçük korulardan oluşmaktadır. Taş evleri ve taş yollarının güzelliğinin yanı sıra adada üretilen uzo, oldukça tanınan geleneksel bir içkidir. Değiş̧ik markalarda ve çeşitli meyve aromaları ile üretilen uzonun birçok aile tarafından üretildiği de bilinmektedir.

Ayvalık’tan yaz aylarında her gün feribotlarla ulaşım sağlanan Midilli adası, geç Neolitik dönemden itibaren insanlar tarafından yerleşim alanı olarak kullanılmaktadır. Aka'lıların MÖ1393 tarihinde adayı ele geçirmesi ile başlayan kültür ve geleneksel yapı daha sonraki dönemlerde Aiol, Roma, Bizans, Ceneviz, Osmanlı ve Yunan toplumlarının etkisinde kalmıştır. Bu süre içerisinde ada halkı inançları, yaşam biçimleri ve kültürleri doğrultusunda kendi geleneksel değerlerini oluşturmuştur. Türk halkı ile Midilli halkı Osmanlı İmparatorluğu döneminde yüz yıllarca birlikte yaşamışlardır (1462-1912). Adanın Yunanistan’a geçmesinden sonra, bölgede yaşayan halkın adadan Anadolu’ya, Anadolu dan adaya mübadil değişimleri olmuştur. Adanın Atina’ya uzak olmasından dolayı halk çeşitli ihtiyaçlarını Türkiye den karşılamıştır. Bu nedenle iki toplum arasında iletişim hiç kopmadan devam etmiş ve kültür benzeşiminden dolayı karşılıklı olarak her iki tarafta da yabancılık duygusu yaşanmamıştır.

Günümüzde Ayvalık ve ada arasında daha çok Türkiyeden adaya yoğun bir turizm haraketliliği olduğu görülmektedir. İki kara arasında mesafenin yakın olması ve ulaşım kolaylığı bu haraketliliği arttırmaktadır. Haraketliliğin bir diğer nedeni ise iki kültürün bir birine çok yakın olması ve inançları dışında yaşamsal, kültürel bir çok ortak değerleri paylaşmalarıdır. Bunun sebebi yüzyıllarca aynı topraklar üzerinde birlikte yaşamış olmaktan ve ortak değerlerde buluşmaktan kaynaklanmaktadır. 


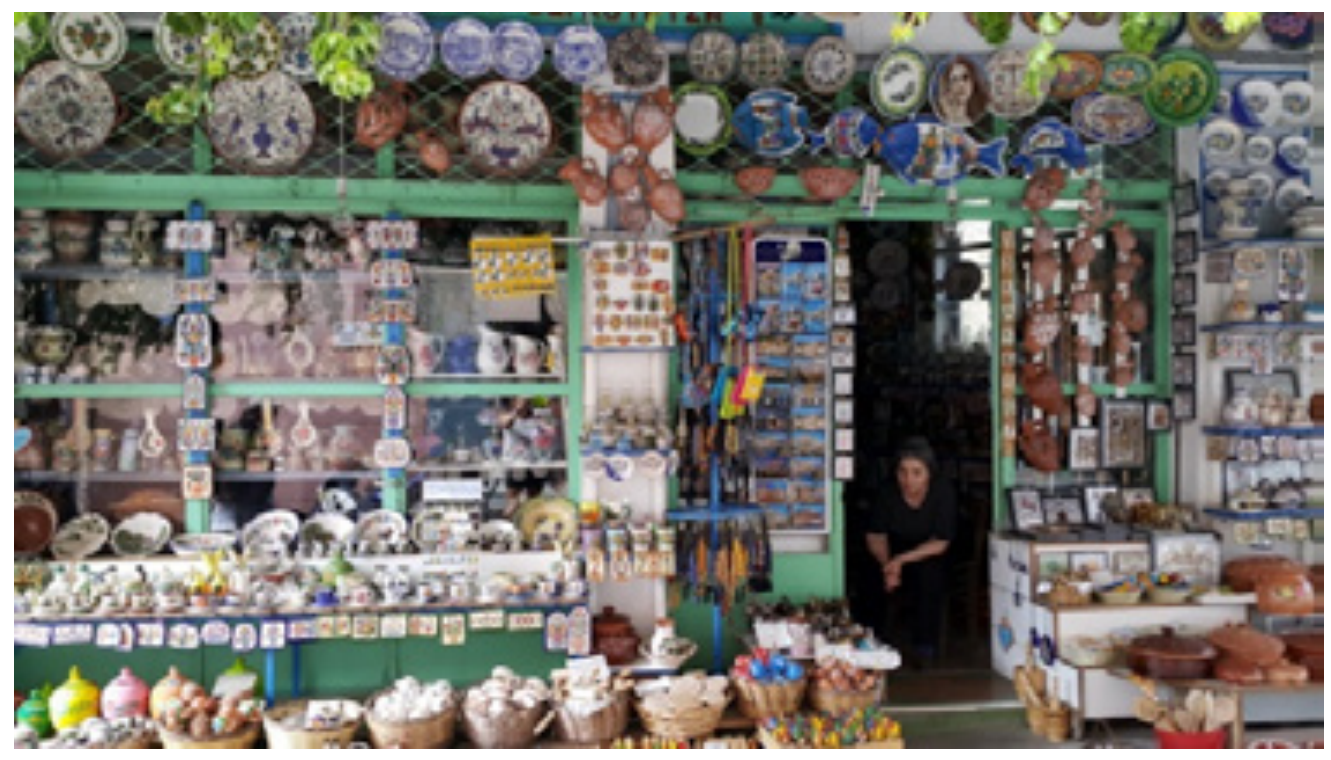

Görsel 1: Ariassos'ta seramik atölyesi ve satış dükkanından görüntü.

Kültür, doğanın yarattıklarına karşılık insanoğlunun ortaya koyduğu maddi, manevi tüm değerlerdir. Midilli adası kültürüne ait geleneksel üretimlere bakıldığında; çömlekçilik sanatının azalarakta olsa günümüzde halen üretime devam ettiği görülmektedir. Çömlekçilik; uygun seramik bünyenin değişik yöntemlerle şekillendirilip, günlük hayatta kullanmak için çeşitli ürünlerin üretilmesi ile ortaya çıan; kültüre ve geleneğe bağlı bir el sanatıdır. Çömlekçilik sanatının bir bölgede gelişebilmesi için uygun ve yeteri kadar kil yataklarının olması gerekmektedir. Çömlekçi ürünlerin imalat şekli, formların biçimi, dekoru ve dekor yöntemleri içinde bulunduğu kültürün yaşamsal ve geleneksel yapılarını yansıtır. Geleneksel olarak üretilen, kültüre ve geleneğe dayalı bu ürünlerin biçimlerinde ve dekorlarında dikkat çeken farklıklar görmek mümkündür. Örneğin tahıl üretilen bölgelerde büyük tahıl küpleri üretilirken; zeytin üretilen bölgelerde yağ küpleri veya deniz taşımacıllğg yapılan bölgelerde amforalar üretilmiştir. Yine kültür ve gelenek farklılı̆̆ı, üretilen kapların dekorlarında da görülmektedir. Günlük yaşamdan kesitler, inançlarla ilgili konular geleneğe ve kültüre bağlı olarak üretilen ürünler üzerine geleneksel bir biçimde dekorlanmıştır.
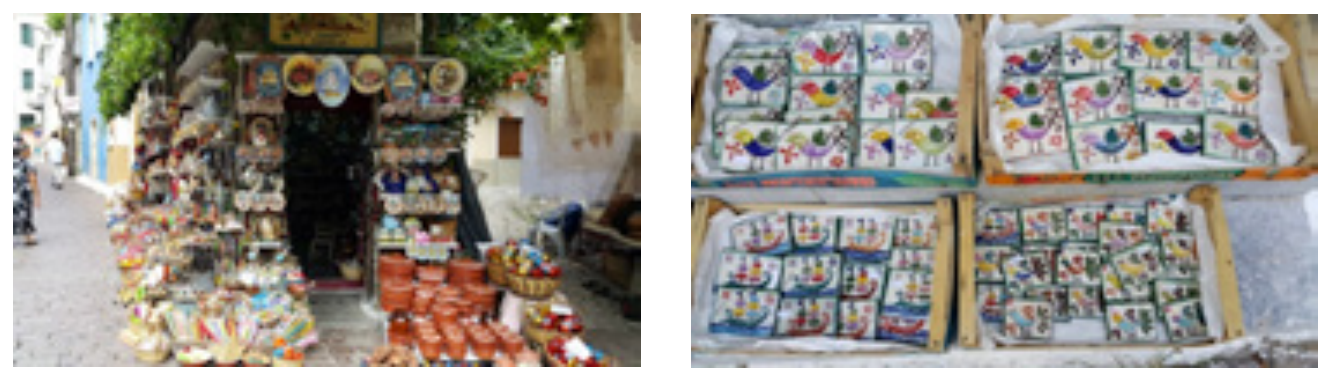

Görsel 2-3: Ariassos'ta seramik atölyesi- satıs dükkanı ve üretilen seramik magnetler. 
Çağdaş yaşam koşulları ve teknolojinin gelişmesine bağlı olarak değişen ihtiyaçlardan dolayı çömlekçilik sanatında da değişimler olmuştur. Bazı atölyeler beklentilere cevap veremediğinden, bazıları ise maddi imkansızlıklar ve talep azlığından dolayı kapatılmak zorunda kalmıştır. Günümüz çömlekçileri de varlığını sürdürebilmek için mevcut şartlara uyum sağlamak zorunda kalmışlardır. Bu anlayışla üretimlerini gelenekselden fazla ayrılmadan, yöresel ve kültürel değerleri ortaya çıartarak turizme yönelik, özgün üretimler yapma eğilimine girmişlerdir. Midilli’ de geleneksel çömlekçiliğin en yaygın olarak yapıldığı yer Mandamadhos köyü olarak bilinmektedir. Mandamadhos adanın kuzeydoğusunda yer almaktadır. Geleneksel mimari karakterinin tamamen korunması ile birlikte, otantik sokakları, taş döşemeli yolları, aynı zamanda hayvancılık ve tarım üretiminin yoğun olarak yapıldığ köy; zeytin ve zeytinyağ 1 ile oldukça ünlüdür. Köyün üretimi ile ünlü diğer bir alanı ise geleneksel çömlekçilik ve seramik eşya ürünleridir.

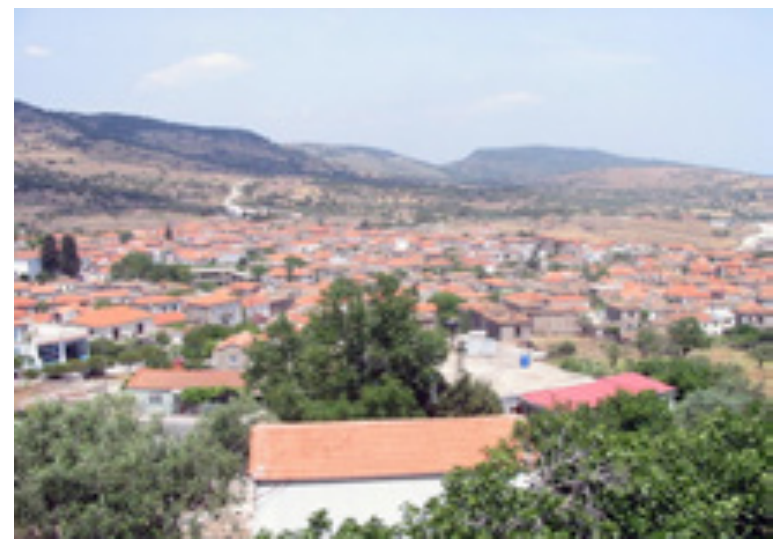

Görsel 4: Mandamadhos dan genel bir görüntü.

Çömlekçilik, Mandamadhos halkı için geçmişten günümüze devam eden geleneksel üretimlerden biridir. Köyde 1900 lü yılların başından kalan taş seramik fırınların sayısına bakıldığında Mandamadhos'un o dönemde önemli bir seramik merkezi olduğu ortaya çıkmaktadır.

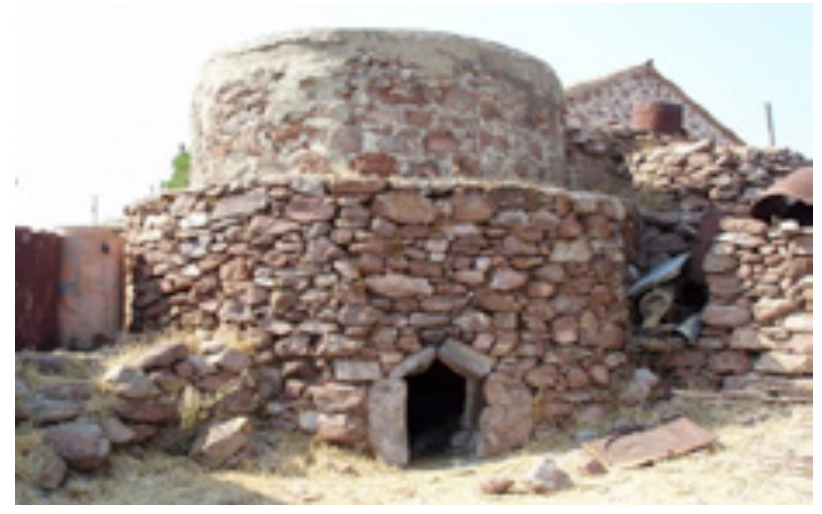

Görsel 5: Mandamadhos da geleneksel seramik firınından bir görüntü. 
Mandamadhos'ta 1950'li yıllarda 60 seramik atölyesinin bulunduğu belirtilirken, bugün bölgede sadece iki atölye faaliyet göstermektedir. Bu durumun ülkemizdeki geleneksel üretim yapan çömlekçi bölgeleri ile aynı kaderi paylaştığı görülmektedir. Geleneksel çömlekçilik üretiminin gerekli ilgiyi görmemesinden, üretim yapacak ustaların yetişmemesi, beklenti ve beğenilerin değişmesinden dolayı çömlekçilik önemini kaybetmiştir. Eskiden kullanılan saklama kapları, su kapları ve günlük kullanım vb. eşyalar nostaljik görselliği dışında günümüzde pek fazla kullanılmamaktadır. Üretilen çömlekçi ürünleri geleneksel özelliğini, kültüre dayalı değerlerinin yanı sıra artistik değerler taşıdığı müddetçe gerekli ilgiyi görmektedir. Bu önemli misyonu üzerinde taşıyan çömlekçi atölyelerinin sayıları az da olsa varlıklarını sürdürmeye devam etmektedirler.

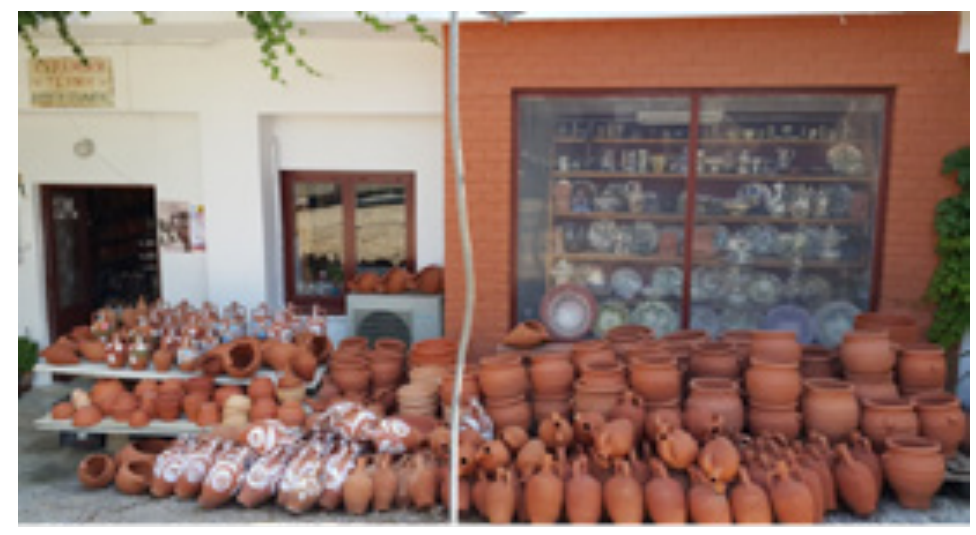

Görsel 6: Mandamadhos da KEPEMIKH TEXNH çömlekçi atölyesinden bir görüntü.

$\mathrm{Bu}$ anlamda Mandamadhos'ta faaliyet gösteren iki atölyeden biri olan KEPEMIKH TEXNH atölyesi dört kuşaktan beri babadan oğula geçen kültüre bağlı olarak geleneksel üretim yapmakta ve misyonunu devam ettirmektedir. Atölyede üretim ailede iş bölümü yapılarak bütün fertlerinin katılımı ile gerçekleştirilmektedir. Tornada geleneksel şekillendirme baba tarafından yapılırken dekorlar ise anne ve kızı tarafından uygulanmaktadır. KEPEMIKH TEXNH çömlekçi atölyesinde tornada kırmızı çamurdan üretilen ürünler; testiler, saksılar, şarap ve yağ kapları, tencereler, duvar tabakları, dekorlu kahve fincanları ve değişik turistik eşyalardan oluşmakta ve pişirim 980-1000 C'de gerçekleşmektedir. 

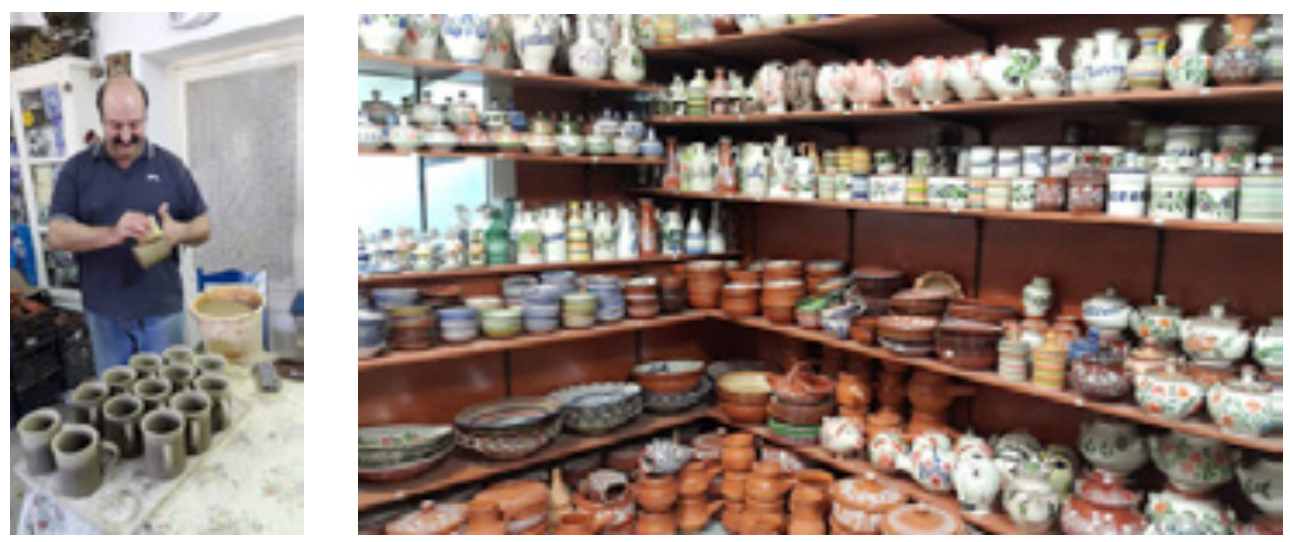

Görsel 7-8: KEPEMİKH TEXNH atölyesinde Panagiotis Stilianos usta çalışırken ve ürünleri.

Köyde geleneksel olarak her yıl Ağustos ayı içerisinde değişik yörelerden çömlekçi ustaları ve seramik sanatçılarının katılımı ile seramik festivali düzenlenmektedir. Festivalin amacı geleneksel üretim yöntemlerinin geliştirilmesi, çeşitlendirilmesi, tanıtımı, bilgi ve beceri aktarımıdır.
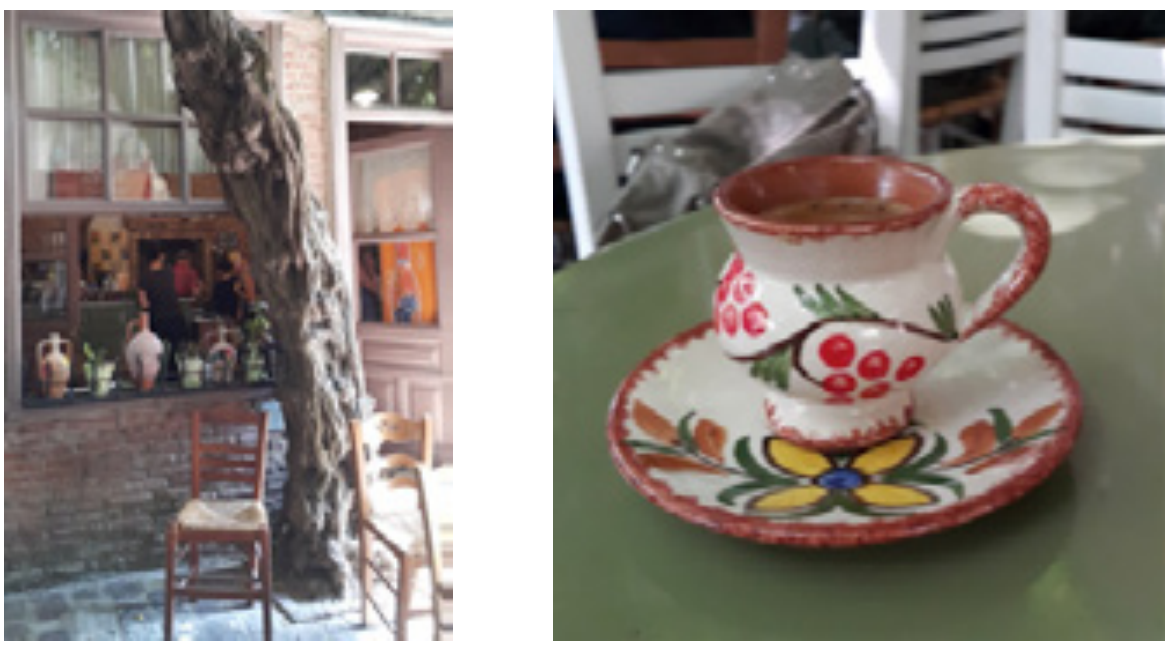

Görsel 9-10: Agiasos'un geleneksel kahvehanesi ve kahve fincanı.

Midillide seramik yapan diğer köy ise Agiasos'tur. Agiasos'un özelliği Bizanslılar döneminde inşa edilen ve bütün Yunanistan'da meşhur olan mucizevi ikonayı bulunduran panagia (Meryem Ana) kilisesidir. Pitoresk taş sokakları, folklorik ürünleri, geleneksel seramik kahve fincanlarında kahvesi ve ağaç oymacıllğı ile dikkat çeken köyde iki adet geleneksel seramik üretim yapan atölye bulunmaktadır. Agiasos'taki seramik atölyelerinde üretilen ürünler de benzer şekilde Mandamadhos'taki gibi ürün çeşitliliği ve özelliği taşımaktadır. 

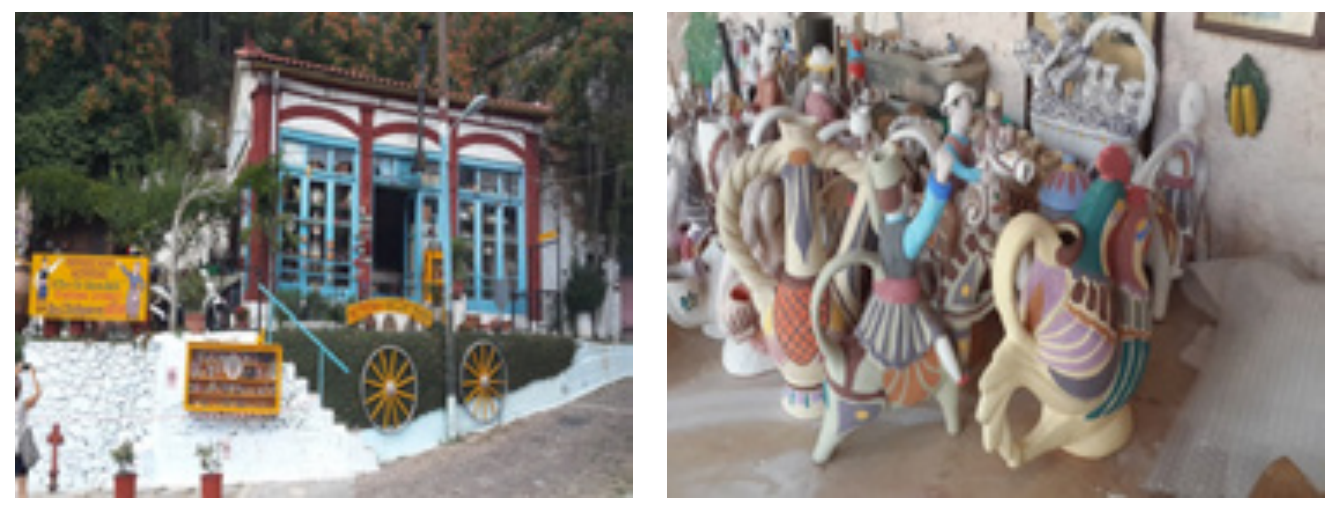

Görsel 11-12: Agiasos'ta Kapodokia Keramika atölyesi ve pişirimi yapılmamış ürünleri.

Midilli’de iki köyde üretilen geleneksel çömlekçi ürünler incelendiğinde ortak özelliklerini; kırmızı çamur veya kırmızı çamur üzerine beyaz astar ve dekorlu, sırsız ürünler veya tamamen astarlanmış ve üzerlerine serbest el dekoru ile renkli boyalarla-oksitlerle dekorlanmış ve sırlanmış ürünler oluşturmaktadır. Form olarak bakıldığında yapılan üretimlerden bazılarının Çanakkale seramikleri ile yakından benzerlik gösterdiği gözlemlenmiştir. Her ne kadar ülkeler ve inançlar ayrı olsa da yakın toplumlar arasında kültür ve gelenek akışı her zaman olmaktadır. Suyun iki yakasına komşu olan yerleşimler arasında ortak kültürlerin olması ve bu kültür akışının seramik üretimine de yansıyarak benzer seramikler üretilmesi çok normaldir. Örneğin Çanakkale testilerinin, yelkenlilerle bezeli duvar tabaklarının oldukça benzerleri Midilli adasındaki seramik atölyelerinde de üretilmektedir. İki toplumda üretilen ürünler gerek form gerekse üretim biçimi olarak benzerlik gösterirken; Midillide üretilen seramik ürünlerin dekorlarında Çanakkale seramiklerinde kullanılan desenlerin yanı sıra farklı desenlerin kullanıldı̆̆ı da görülmektedir.

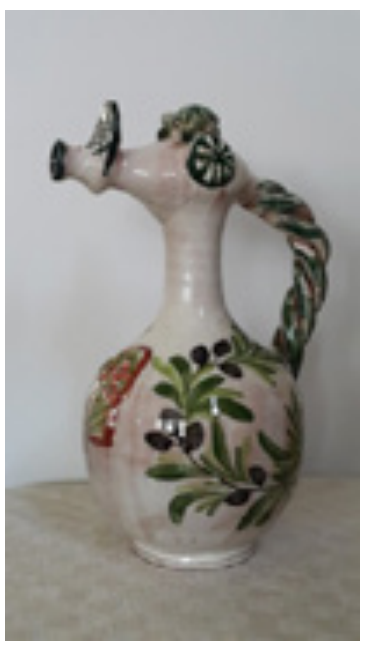

Görsel 13: KEPEMIKKH TEXNH atölyesinde üretilen sürahi, $35 \times 15 \mathrm{~cm}$.

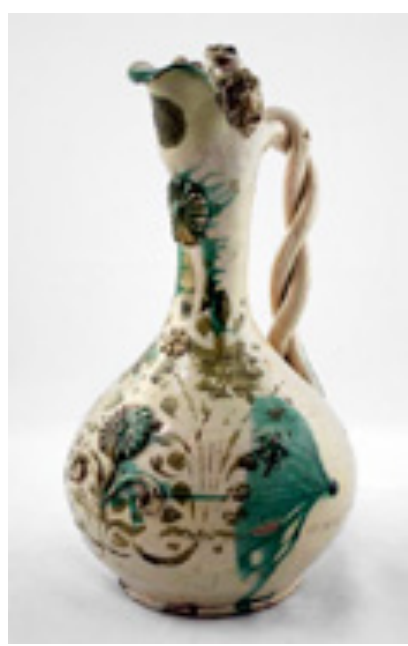

Görsel 14: Çanakkale Seramiği, 19. yy, Suna-İnan KIRAÇ kolleksiyonu, $35.9 \times 10.6 \times 15.5 \mathrm{~cm}$ 
Bilindiği gibi zeytincilik, balıkçılık, bağcılık halkın ana geçim kaynağıdır. Bu durumdan etkilenen çömlekçiler ürettikleri seramik ürünlerin üzerine yaşamlarının bir parçası olan zeytini, denizi, deniz ürünlerini çok güzel bir şekilde betimleyip kendilerine has dekorları ile yorumlayarak uygulamalar yapmışlardır. Ürünlerin üzerlerindeki dekorların desenlerini; daha çok zeytin, zeytin dalı, çiçekler, balık, çeşitli deniz ürünleri, yelkenli ve güncel yaşamın temaları yalın ve naif bir şekilde oluşturmaktadır.

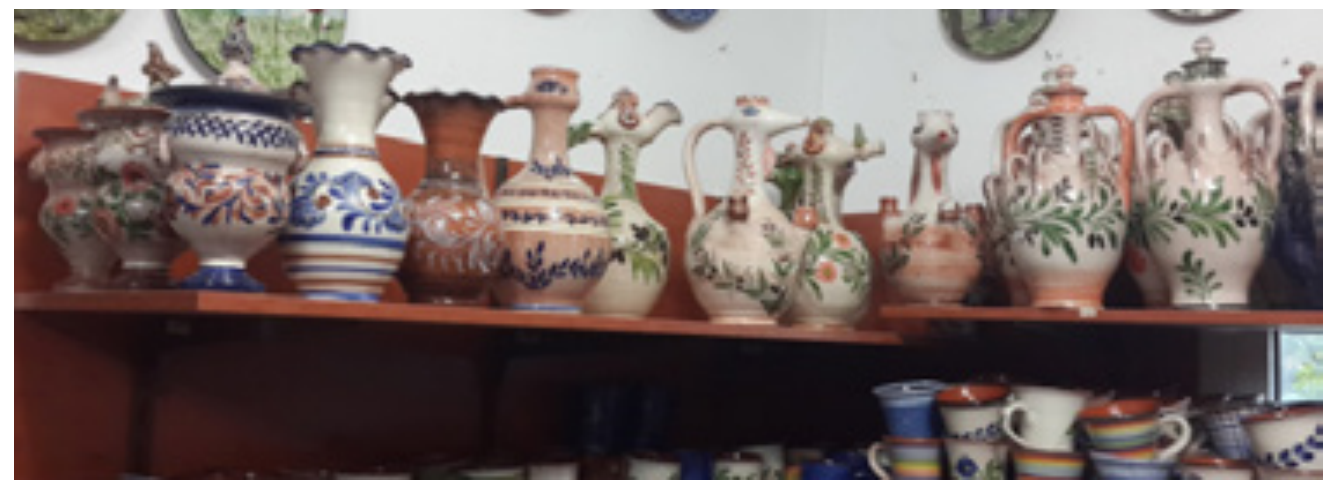

Görsel 15: KEPEMİKH TEXNH atölyesinde üretilen zeytin ve zeytin dal dekorlu seramik formlar.

Dekorlu seramiklerin yanı sıra pişirilmiş ürünlerin üzerinde ülkemizde olduğu gibi ne yazık ki sentetik boyalarla dekorlanmış bazı süslemeler görülmektedir. Bu ürünler genel olarak çeşitli dekoratif kaplardan, yel değirmenlerinden, biblolardan ve turistik eşyalardan oluşmaktadır. Ada kültürünü yansıtan el ile dekorlanmış güzel ve özgün ürünlerin beraberinde sunulan bu ürünler asıl geleneksel üretimlerin yanında kötü örneklerdir. Toplumların gelenek ve kültürleri birbirlerini etkilerken bazen bu örnekte de olduğu gibi olumsuz etkileşimlere de rastlanmaktadır. Seramiğin özüne aykırı yapılan bu uygulamalar çömlekçilik sanatını geleneksel boyutundan uzaklaştırmaktadır. Bu tarzda üretilen ürünler, seramiğin doğasından uzaklaşarak basit, kötü ve sentetik bir yapıya bürünerek kültür yozlaşmasına neden olmaktadır. Ülkemizde de bir dönem yoğun olarak yapılan bu uygulamadan vazgeçilerek öze dönülmeye başlanmıştır.
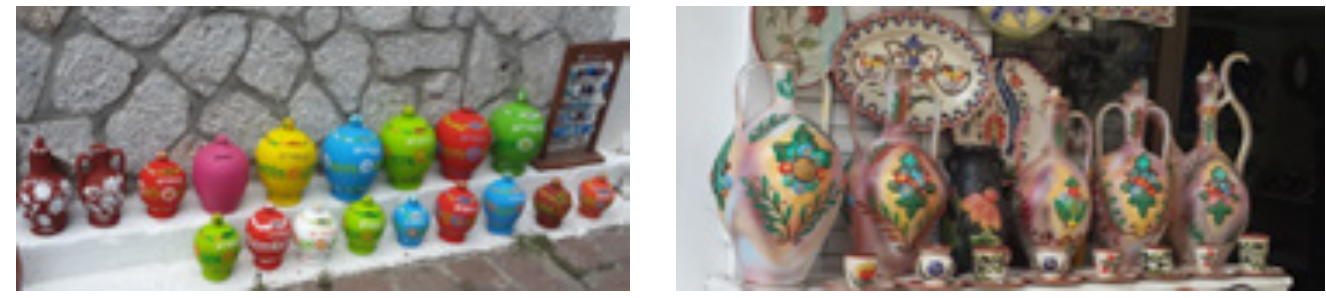

Görsel 16-17: Midilli adasında sentetik boyalarla dekorlanmış seramik örnekler. 
Ada çömlekçiliğinde üretilen özgün çömlekçi formlar; içinde bulunduğu ada kültürünü ve beğenilerini yansıtmasının yanı sıra iki ülke ve toplum arasındaki kültür etkileşiminin ve paylaşımının güzel örneği olarak kendilerini göstermektedir. Her şeyin çok hızlı değiştiği günümüzde, kendi kültürüne sahip çıkıp geleneğini sürdürmenin zorluğunu yaşayan Midillideki çömlekçilik sanatı; Türkiye'de olduğu gibi direnerek, geleneği ve kültürü doğrultusunda varlığını sürdürme yolunda üretimine devam etmektedir. 


\section{KAYNAKÇALAR}

DEMİREL, Özcan (2015), Öğretim İlke ve Yöntemleri Öğretme Sanatı, Pegem Akademik Yayıncılık, 21. Baskı ANKARA http://www.asmandamados.com/-en.htm.

(http://www.lesvosgreece.gr/tr/mandamadhos

http://www.cerameus.gr/en/news-announcements/saturday-august-11th-mantam

https://scontent-vie1-1.xx.fbcdn.net/hphotos-xpf1/v/t1.0-9/1625769_244144610326_6006021_n.jpg?oh=f91bb27d50840 67364430ad246aaf647ఓoe $=563 E 6 E 9 E$

http://www.cerameus.gr/en/news-announcements/saturday-august-11th-mantam

https://www.google.com.tr/search?q=\%C3\%A7anakkale+seramikleriઐtbm $=i s c h \& t b o=u$

Mandamadhos Broșürü,2008

MIRİTZIS, Panagiotis,Midill, Turizm Rehberi, Lesvos

Panagiotis Stilianos usta ile 22 Ağustos 2015 tarihinde yapılan görüşme

http://www.gundemturkiye.com/toplum/kultur-gelenek-ve-toplum-iliskisi.htm

http://www.lesvosgreece.gr/en/mantamados-kapi-pelopi-kli

Görseller yazara aittir. 
